\title{
User-experiences with a web-based self- help intervention for partners of cancer patients based on acceptance and commitment therapy and self-compassion: a qualitative study
}

\author{
Nadine Köhle ${ }^{1 *}$, Constance H. C. Drossaert ${ }^{1}$, Jasmijn Jaran ${ }^{1}$, Karlein M. G. Schreurs ${ }^{1,2}$,
} Irma M. Verdonck-de Leeuw ${ }^{3,4}$ and Ernst T. Bohlmeijer ${ }^{1}$

\begin{abstract}
Background: Partners of cancer patients are the cornerstone of supportive cancer care. They assume different roles and responsibilities that optimally support the patient. Such support is highly demanding, and many partners report (mental) health problems. However, many of them do not use professional supportive care themselves. Offering a Web-based self-help intervention based on Acceptance and Commitment Therapy (ACT) and self-compassion could be an important resource to support this group. This qualitative study aimed to examine user-experiences with a Web-based self-help intervention based on ACT and self-compassion among partners of cancer patients.

Methods: Individual in-depth interviews, about partners' appreciation of the intervention and lessons learned, were conducted with 14 partners of cancer patients who used the Web-based self-help intervention. Interviews were audio-recorded, transcribed verbatim and analyzed by three independent coders both deductively and inductively.

Results: In general, partners appreciated the intervention, however, they also expressed ambivalent feelings towards peer support, the content of the feedback of their counselor, and the 'tunneled' structure of the intervention. The majority of the partners reported being more self-compassionate accepting that they experienced negative thoughts and feelings, they reported that they learned to increase the distance between their thoughts and themselves, they indicated being more aware of their personal values, and they thought that they were better able to commit to those values. They also reported other (non-specific) helpful processes such as insight and acknowledgement, positivity, the possibility to tell their story, time for themselves, and feeling closer and more connected with their partner (the patient).

Conclusions: Partners of cancer patients indicated to appreciate the Web-based self-help intervention based on ACT and self-compassion. They felt that the intervention helped them to cope with negative emotions, thoughts, and one's suffering; to practice self-kindness; and to clarify values based on difficult recent experiences. In addition, they felt that the intervention supported them to obtain insight and acknowledgement, positivity, to tell their story, make time for themselves, and feeling closer and more connected with the patient. We think that a Web-based psychological intervention based on ACT and self-compassion may be a valuable contribution in supporting partners of cancer patients.
\end{abstract}

Keywords: Acceptance and commitment therapy, Self-compassion, Cancer, Oncology, Partner, Web-based interventions, User experiences, Qualitative, Interview

\footnotetext{
* Correspondence: n.kohle@utwente.nl

'Department of Psychology, Health \& Technology, University of Twente, P.O.

Box 217, 7500 AE Enschede, The Netherlands

Full list of author information is available at the end of the article
} 


\section{Background}

Partners of cancer patients have to cope with multiple challenges, including the fear of an unpredictable future and possible death of the patient, feelings of guilt, inadequacy (always wishing to do more), self-doubt and frustration [1]. High levels of distress and caregivers' strain have been demonstrated in many studies (e.g., [1-3]). However, offering support to partners can be challenging as most partners are extremely busy (e.g., [1]). Web-based interventions could be a solution as they are easily accessible and flexible to use [4]. Therefore, we developed - in close cooperation with partners of cancer patients - the Web-based self-help intervention Hold on, for each other. This intervention is based on Acceptance and Commitment Therapy (ACT; [5]) and self-compassion. ACT is a distinct model of behavioral therapy that aims to improve the psychological flexibility of people. It helps people accept what is out of their control (e.g., distressing feelings) and to commit to actions that enrich their lives [6]. The acronym ACT stands for (A) accept your thoughts and feelings, and be mindfully present; $(\mathrm{C})$ choose values that are important in your life (e.g., openness); and (T) take action towards your values (e.g., sharing emotions openly with the partner). Another important component of ACT is cognitive defusion, which is not focused on changing the frequency or content of negative thoughts, but rather to change the relationship people have with their thoughts [7]. ACT has been proven effective for a variety of problems, including chronic pain [8], depression and anxiety [9-11]. However, as far as we know, it has not been applied in interventions for partners of cancer patients despite being potentially useful. Partners of cancer patients are often entangled with unhelpful thoughts (such as "What if the cancer comes back?") and distressing feelings such as guilt, fear and anxiety (e.g., [1]). We think that ACT can help partners to experience these difficulties without resisting them, allowing them to live according to their values, applying them as corresponding actions in their lives and relationships, despite the barriers that can occur due to the cancer.

Self-compassion is defined as the ability to hold one's feelings of suffering with a sense of warmth, connection and concern $[12,13]$. Neff $[12,13]$ proposes three major components of self-compassion: self-kindness versus self-judgment, common humanity versus isolation, and mindfulness versus over-identification. According to Neff $[12,13]$, self-kindness refers to the ability to treat oneself with care in times of distress rather than harsh self-judgment. Common humanity entails recognizing that imperfection is a shared aspect of the human experience rather than feeling isolated by one's failures. Mindfulness in the context of self-compassion is about holding one's painful thoughts and feelings in balanced awareness rather than over-identifying with them. Research has demonstrated that higher levels of self-compassion are related to greater psychological health (in terms of less depression and anxiety) [14], greater happiness, optimism and life satisfaction $[15,16]$, greater relational well-being [17] and appears to be a powerful source of coping and resilience in times of distress (e.g., [18]). Although self-compassion has not been studied in the context of partners of cancer patients, it might particularly be useful for them because they often have unrealistically high expectations of themselves $[1,19,20]$ and many also experience feelings of guilt for not doing enough for their ill partner or whenever they engage in personal activities even while their partner is suffering [1, 21]. Self-compassion may help partners of cancer patients renew their physical and emotional energies (e.g. through taking some time off from caregiving activities and spending some personal time), and enhance their emotional resources (e.g. resilience), both vital activities when coping with the challenges of being a caregiver [22].

$\mathrm{ACT}$ and self-compassion are closely related. Both approaches focus on improving mindfulness, helping people to defuse from their negative thoughts, and stimulating them to live in accordance with their personal values [23]. However, when compared to ACT, self-compassion is more explicitly focused on developing "the capacity for awareness of suffering and the motivation and ability to alleviate or prevent suffering we encounter" [23]. Considering the fact that partners of cancer patients often have high expectations of themselves and they would do anything - regardless the consequences for their own health - for their ill partner [24], self-compassion can particularly be relevant to them and the combination of ACT and self-compassion seems suitable for this target group.

Although ACT and self-compassion are increasingly being used as a theoretical framework for supportive (Web-based) interventions for a number of conditions (e.g., [8-11, 25]), most studies have been quantitative. Qualitative research is essential because it can reveal recommendations for improvement of interventions and valuable information about reasons for success and failure of an intervention [26]. Qualitative results can also provide insights into what the active ingredients of an intervention are [27] and if the underlying theory is appropriate [26].

The aim of this qualitative study was to explore the user-experiences with a Web-based self-help intervention Hold on, for each other among partners of cancer patients. The following questions were addressed: (1) Which elements of the intervention were appreciated by the participants and what suggestions do they have for improvements? (2) What did participants learn from the intervention? The results of this study will help to interpret the effectiveness of Web-based self-help interventions targeting partners of cancer patients (Table 1). 


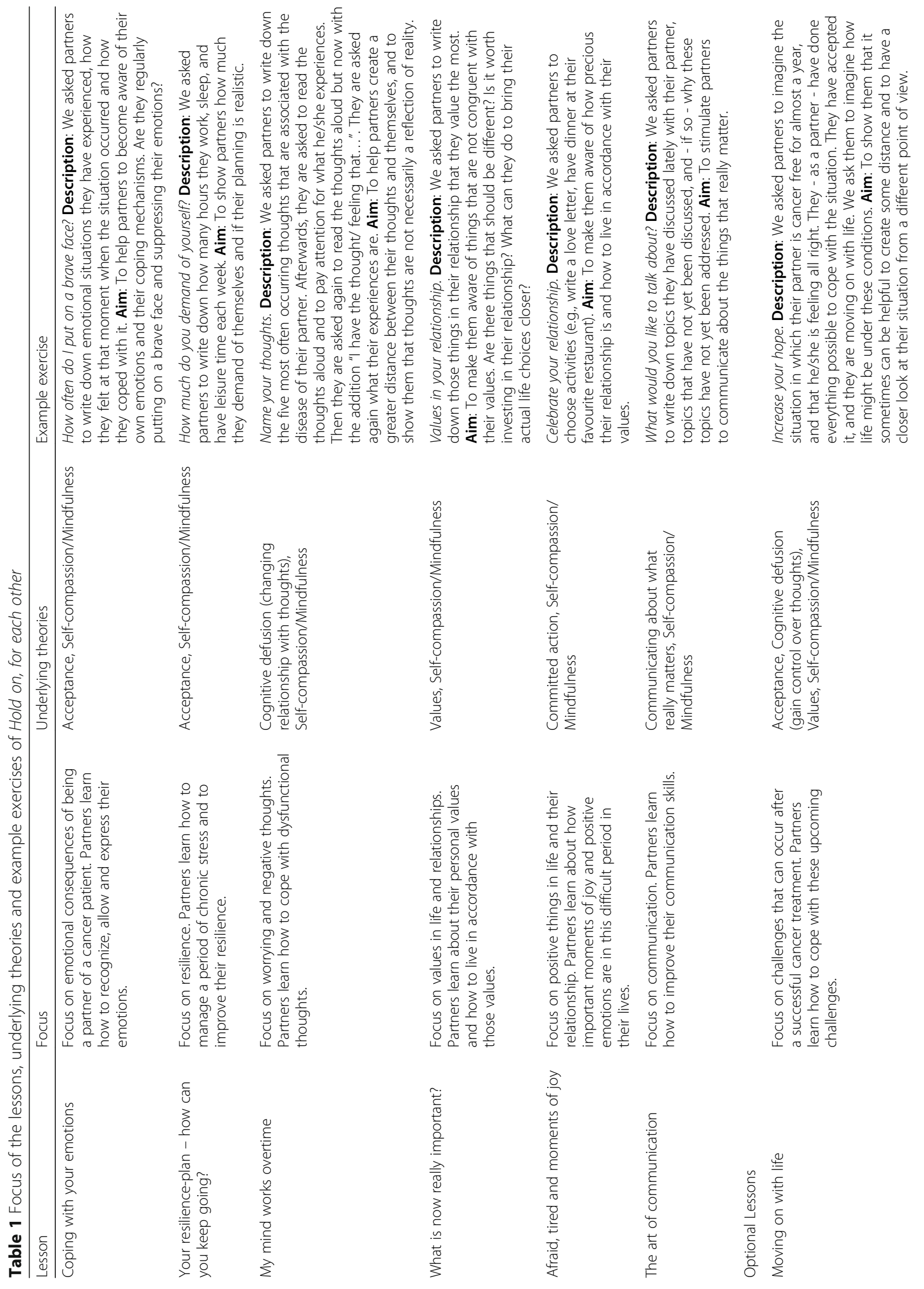




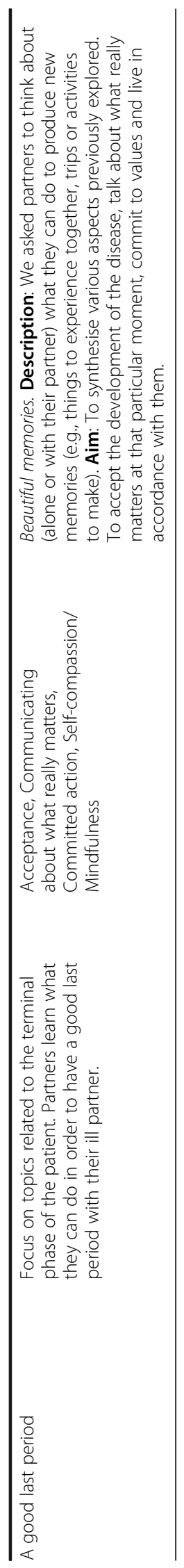




\section{Methods}

\section{Study sample and procedures}

Partners of cancer patients were recruited from an ongoing randomized controlled trial (RCT) [28]. More detailed information about this RCT is presented in the study protocol [28]. At the moment of data collection for the current study, 52 partners of cancer patients had completed the Hold on, for each other intervention as well as the three- and six-months measurements after the baseline measurements. Of this group, 30 partners had indicated that they were willing to participate in the interview, and we randomly selected 20 partners for this study. Partners were contacted by e-mail and invited to participate in a telephone interview about their experiences with Hold on, for each other. Attached to the e-mail, they received the interview questions as well as a short summery of every lesson. With partners who were willing to participate, an appointment for a telephone interview was made. In total, 14 interviews were conducted. Five out of the twenty partners could not be reached and one partner withdrew from participation. The personal characteristics of the partners and the cancer-related characteristics of the patients are listed in Table 2. The mean age of the partners was 55 years old, and the majority were female, highly educated and employed. The patients were diagnosed with a variety of cancers. In most cases, the diagnosis was 15 years ago, and the partners mostly stated that their ill partner was unlikely to be cured. The time since participation varied among participants (mean time since intervention was about 8.6 months).

Once the partners had given their oral informed consent (written informed consent had already been given in the context of the RCT), the interview took place. The interviews were conducted in Dutch by a masters student of Health Psychology (JJ), who had been trained in conducting interviews. During the first three interviews, the student was supervised by a psychologist and the researcher of the RCT (NK). We decided not to include more participants when we found that no new information was found in the last three interviews, indicating that data saturation had been reached after the 14 interviews [29]. All interviews were audiorecorded and transcribed verbatim. The first author of this paper (NK) checked in a random sample of five interviews if the recordings were transcribed accurately. This could be confirmed. The interviews took between 15 and 60 minutes, with an average duration of 30 minutes. Testimonies appearing in this article have been translated from Dutch into English by an outsourced professional (native) translator. Personal characteristics of the partners and cancer-related characteristics of the patients were gathered in the context of the RCT.
Table 2 Personal characteristics of the partners and cancer-related characteristics of the patients $(N=14)$

\begin{tabular}{|c|c|}
\hline Characteristics & N \\
\hline Gender (female) & 11 \\
\hline Age years, mean (S.D.); [range] & $55.3(9.3)$ [34-68] \\
\hline Country of birth (the Netherlands) & 14 \\
\hline \multicolumn{2}{|l|}{ Education } \\
\hline Low & 2 \\
\hline Middle & 6 \\
\hline High & 6 \\
\hline \multicolumn{2}{|l|}{ Employment } \\
\hline Employed (>20 hours per week) & 8 \\
\hline Unemployed/retired & 6 \\
\hline \multicolumn{2}{|l|}{ Children } \\
\hline No/or living away from home & 10 \\
\hline Yes, living at home & 4 \\
\hline \multicolumn{2}{|l|}{ Type of cancer } \\
\hline Colon cancer & 2 \\
\hline Kahler's disease & 2 \\
\hline Lung cancer & 2 \\
\hline Prostate cancer & 2 \\
\hline Leukemia & 1 \\
\hline Bladder cancer & 1 \\
\hline Lymph node cancer & 1 \\
\hline Pancreatic cancer & 1 \\
\hline Head- and neck cancer & 1 \\
\hline Breast cancer & 1 \\
\hline \multicolumn{2}{|l|}{ Time since diagnosis } \\
\hline 3-6 months & 4 \\
\hline $1-5$ years & 8 \\
\hline $5-10$ years & 1 \\
\hline$>10$ years & 1 \\
\hline \multicolumn{2}{|l|}{ Treatment } \\
\hline No & 5 \\
\hline Yes & 9 \\
\hline \multicolumn{2}{|l|}{ Stage of disease } \\
\hline Patient is still in treatment with curative intent. & 4 \\
\hline $\begin{array}{l}\text { Treatment with curative intent is completed; } \\
\text { patient is recovered. }\end{array}$ & 1 \\
\hline Patient will (probably) not recover. & 9 \\
\hline
\end{tabular}

\section{Description of Hold on, for each other}

Hold on, for each other (see Fig. 1 and Table 1) is an intervention that aims to help partners to positively persevere during the difficult times they find themselves facing. Built and co-created with partners in order to ensure it complies with their needs and wishes, 

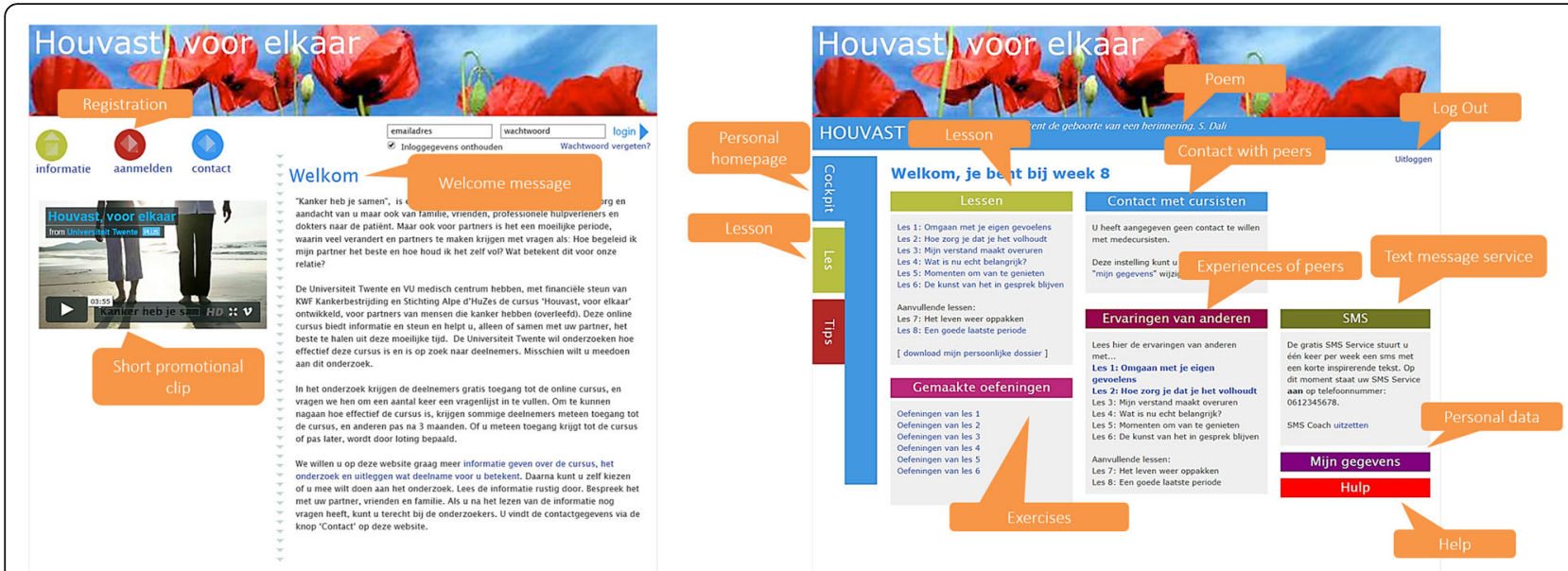

Fig. 1 Screenshots of the Hold on, for each other website and personal homepage

the intervention consists of six lessons, and in each lesson one particular theme is discussed (see Table 1). The intervention makes use of tunneling, which means that partners were guided through the intervention [30]. First-time users were tunneled through two information pages in order to introduce them to the different components of the intervention. The content of each lesson and the lessons themselves were delivered in a predetermined sequence of steps. A next page or lesson could only be accessed when the previous page or lesson was completed. The aim of this tunneled structure was to enhance the change process of the participants by offering them the most appropriate intervention content at a particular moment in time [31].

Every lesson starts with a short text about the topic of that lesson. The core messages of ACT and selfcompassion are integrated in these texts (see Table 1). The texts are enriched with short psychological exercises that are based on ACT and self-compassion. Each lesson also contains a mindfulness exercise based on self-compassion, that can be read or downloaded as a mp3-file. Partners also receive practical information, tips and references to relevant websites. Users can freely decide if they want to receive text messages (one per lesson) with short inspiring texts. Moreover, partners have different options to come into contact with peers. Previous studies pointed out that people often fear peer contact because they are afraid of being confronted with negative stories [32,33]. To minimize this risk, Hold on, for each other offers three kinds of peer support. First, partners can share their answers on some exercises with other participants (and read the answers given by other participants). Second, they can share (and read) tips and advice, and third, they can contact other partners by sending a private message (message system is integrated in the website of the intervention). All the components are optional, and partners can decide freely to use them or not. Partners also receive support: automated support or personal support (weekly feedback messages from a personal online counselor (a trained masters psychology student of the University of Twente, The Netherlands), explained in more detail in study protocol [28]).

\section{Interview scheme}

A semi-structured interview scheme was used. Partners of cancer patients were asked about experiences regarding the: (a) Web-based intervention in general; (b) psycho-education (lessons and psychological exercises); (c) mindfulness exercises; (d) peer support; and (e) practical information, tips and references. For each of these topics, partners were asked about what they appreciated, if they had any suggestions for improvements, and what they had learned. During the interview, partners were encouraged to motivate their answers and experiences.

\section{Data analysis}

Two coders (JJ, NK) analyzed the data with the use of open coding, axial coding and selective coding, applying deductive and inductive analysis [34, 35]. First, the coders independently selected relevant fragments and coded them in one of two predefined categories: evaluation of the intervention and the lessons learned of the intervention. Afterwards, inductive analysis - meaning that subthemes derived from data, instead of predefined categories - was further used to categorize all fragments into subthemes. After every five interviews, the coders met to discuss their subthemes. When dissimilarities were found, the two coders reached a consensus and the coding scheme was redefined. After all codes have been obtained, code schemes with exemplary codes were developed by constant comparison of similarities and differences in the 
data [35]. When the two coders finished their analysis, a third researcher $(\mathrm{CHCD})$ checked the categorization and the three researchers further discussed any disagreements about the categories. Final categories were defined on the basis of consensus between the three researchers.

\section{Results}

\section{Partners' evaluation of the intervention}

In the next sections, the partners' evaluation of the intervention is described, starting with more general comments and followed by their evaluation of the following components of the intervention: psycho-education (lessons and psychological exercises); mindfulness exercises; peer support; practical information, tips, references and text message service; and personal support (see Table 3). Some partners mentioned arguments for both why they appreciated a specific element or why they did not appreciate it. Therefore, the number of participants not always adds up to 14. In addition to the evaluation, an overview of the partners' suggestions regarding both the improvement of the intervention and a dissemination of such an intervention is provided.

The general comments were divided into six categories: (1) unspecified; (2) structure/design; (3) topics addressed; (4) flexibility; (5) anonymity; (6) (positive) approach. Unspecified comments included quotes such as "I thought it was a very interesting course." Seven partners mentioned that they appreciated the structure and design of the intervention: as illustrated by the following comment from a partner" "I am always amazed how well it is made, and how many great elements it comprises." However, four partners were less satisfied with the structure and the fact that they were guided through the intervention, because they felt it was unclear or did not fit their needs. As one of the partners said:

Table 3 Partners' evaluation of specific parts of the intervention

\begin{tabular}{|c|c|c|c|c|}
\hline Category & $\begin{array}{l}\mathrm{n}^{\mathrm{a}} \\
\text { pro }\end{array}$ & Pro argument & $\begin{array}{l}\mathrm{n}^{\mathrm{a}} \\
\text { against }\end{array}$ & Against argument \\
\hline \multirow[t]{3}{*}{ Psycho-education } & 14 & & 10 & \\
\hline & & - General comments; unspecified & & - Not personally relevant \\
\hline & & & & - Particular exercise not appealing \\
\hline \multirow[t]{3}{*}{ Mindfulness exercises } & 10 & & 3 & \\
\hline & & - Exercises are pleasant, fun, interesting and relaxing & & - No need for mindfulness exercises \\
\hline & & & & - Mindfulness exercises are not appealing \\
\hline \multirow[t]{9}{*}{ Peer support } & 3 & & 12 & \\
\hline & & - Possibility to exchange tips and experiences with peers & & - No need for peer support \\
\hline & & & & - Sufficient support from personal network \\
\hline & & & & - Afraid of being confronted with negative stories \\
\hline & & & & - No capacity to listen to the story of another partner \\
\hline & & & & - Doubting that peers could help each other \\
\hline & & & & - Preference to stay anonymous \\
\hline & & & & - Web-based support felt too impersonal \\
\hline & & & & $\begin{array}{l}\text { - Afraid that personal situation is not comparable to } \\
\text { that of others }\end{array}$ \\
\hline \multirow{4}{*}{$\begin{array}{l}\text { Practical information, } \\
\text { tips and references; } \\
\text { text message service }\end{array}$} & 6 & & 3 & \\
\hline & & - Pleasant to read & & - Information not personally relevant \\
\hline & & - Useful information & & - No need for this information \\
\hline & & & & - No time to read long texts \\
\hline \multirow[t]{4}{*}{ Personal support } & $1^{\mathrm{b}}$ & & $4^{b}$ & \\
\hline & & General argument; not further specified & & $\begin{array}{l}\text { - Preference for more personal feedback instead of } \\
\text { feedback on progress using the intervention }\end{array}$ \\
\hline & & & & $\begin{array}{l}\text { - Preference to have the opportunity to talk to a } \\
\text { professional from time to time }\end{array}$ \\
\hline & & & & - Language of feedback messages was not appealing \\
\hline
\end{tabular}

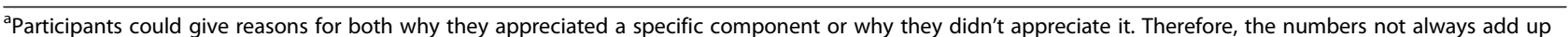
to 14

${ }^{\mathrm{b}} \mathrm{Six}$ of the partners received support from a personal counselor during the intervention. Five of them talked about what they appreciated or didn't appreciate about this element 
I noticed during the course that it was difficult to adapt my life and its rhythm to the rhythm of the course. Of course one does not have exactly those needs in exactly that order... I can imagine it was carefully thought out, but it did sometimes feel like someone was stepping on the brake.

Five partners particularly appreciated the topics addressed in the intervention, because they fit their personal situation and were highly relevant for partners of cancer patients. One partner mentioned: "The words 'Hold on' [in the intervention's name] say it all, since it is something to 'hold on' to. Wherever or whenever, people profit from it. For one person, this element is important, for another person, another element." Four partners indicated that certain topics were not that relevant for them, as one partner mentioned in the following quote: "Some parts made me think, this doesn't mean anything to me."

Four partners liked the flexibility of the intervention. They appreciated that no exercise was mandatory, but that you could freely decide what you wanted to use and how you wanted to use it. One partner said: "I appreciated being able to follow at my own pace, to be busy with ... let's say ... formulating my thoughts and feelings."

Two partners liked that they could stay anonymous, and one partner particularly liked the positive nature of the intervention and the way partners were approached:

Also the care with which [the researchers designed and formulated] everything. Yes, I think it deserves a big A. Also how you [designed the intervention to] approach people, in such a pleasant way. In any case, the threshold is low, so one does not get the feeling one is doing things the wrong way.

\section{Evaluation of psycho-education (lessons and psychological exercises)}

While the partners did not cite any particular lesson, they all mentioned reasons why they liked the psychoeducation. Five partners reported an appreciation for general aspects. For example: "And then I sent it off and waited excitedly for the next session", or "We participated with a lot of pleasure and greatly profited from it." Other partners highlighted why they liked a particular topic or exercise. For example, one partner appreciated "... the first lesson, in particular, especially because it made you express your feelings and put them into words, since we are always so busy with other people." Another partner said: "And that lesson [6] arrived just in time for me, which struck me again. Just spit it out and type or write it down, and then you are rid of it..."

Ten partners also mentioned some particular aspects of the intervention that they appreciated less. Four partners mentioned that (some parts of) the psychoeducation were not relevant for them, as illustrated in the following quote: "I can't name any examples now, but there were questions that I kind of skipped, though I don't remember what they were. I didn't think they applied to me." Five partners indicated that they did not like one particular exercise, called "The answers to whatif questions," for numerous reasons. One felt that this exercise was particularly unappealing, for example: "I always consider what-if questions senseless." Another felt the exercise was too negative: "I'm not busy with such what-if questions, but try to think in terms of solutions. So I don't always worry like 'imagine that ...' I'd rather think in terms of positive solutions." Still others felt that such what-if questions were too difficult to think about. One partner explained: "I really found what-if questions quite complicated." However, this exercise also helped some partners to cope with difficult thoughts, which we later describe in the section about long-term effects.

\section{Evaluation of mindfulness exercises}

Ten partners appreciated the mindfulness exercises because they experienced them as pleasant, fun, interesting and relaxing. One partner explained this appreciation as follows: "Yes, very pleasant. In the beginning, at first, I thought: what I am doing here? But then gradually... it was very pleasant."

Three partners were more critical, indicating that they had no need for such exercises or that the exercises were not appealing to them, for example: "I didn't have much use for it. At that moment, I was too busy for it, and anyway, it wasn't really my thing."

\section{Evaluation of peer support}

Two partners appreciated the possibility of having contact with peers because they were interested in sharing their tips and experiences and reading the tips of others. As one of them said: "They offered tips, and I always read those, which I thought was really great." However, the majority of the partners did not use the peer support, and some of the partners had multiple reasons for not doing so. Reasons for this included that six partners did not need peer support or three of them mentioned that they had sufficient support from their private network, as one partner explained: "I didn't feel the need for it, since I am in such close contact with my friends and family." Other reasons for not using the peer support were: three partners were afraid of being confronted with negative stories; three partners had no emotional energy for the story of another partner; two partners were doubting that peers could help each other; one partner wanted to stay anonymous; for two partners peer support via the intervention felt too impersonal; and two partners were afraid that their situation was 
not comparable to that of others, as is illustrated in the following quote:

It was also difficult for me, because I realized that amongst the fellow participants, there were some whose partners were terminally ill. Since that is not my situation, I feel very privileged and would not dare to come forward with my things, which are really not that bad... You could also read about the situation they were in, which, yes, made me feel ashamed of sharing my things.

Evaluation of practical information, tips and references, and text message service

Six partners appreciated the practical information because it was pleasant to read and contained useful information as illustrated in the following comment of one of the partners: "I recall those tips... those summaries of all the information. I did appreciate all those practical tips a lot, just reading through them once." Two partners mentioned that they appreciated the text message service. One of them described the appreciation as follows: "I really liked them and also showed them to [my partner], like: 'Now see what I got!'”

Three partners did not like the practical information, because one of them felt that the information provided was not relevant for them, another one was not in need of such information, and one partner had no energy to read long texts: "I was not in the mood to read long texts, so I just forgot about it."

\section{Evaluation of personal support}

Six of the partners received support from a personal counselor during the intervention. One participant didn't mention if he/she appreciated this component. One participant reported being satisfied with the personal counselling: "Yes, that was very nice, it was really nice to get personal support."

Four partners were not entirely satisfied with the support provided by their counselor because they had expected personal feedback instead of feedback that mostly targeted their progress in the intervention. They would have liked to have the possibility to talk to a professional from time to time, for example via telephone, because then they might have the opportunity of discussing matters more deeply. This contact could also function as a motivator to stay engaged with the intervention. One partner felt that the language of the feedback messages was obviously language social workers use:

'How good of you' and 'Nice to hear' and 'Oh well, that doesn't matter.' Yeah, I thought, come on, I'm 60. A further disadvantage is that I am a social worker myself, so that is really social worker's language that really doesn't work for me.

\section{Suggestions for improvement and dissemination of the intervention}

In addition to the suggestions for improvement of the intervention (less rigid structure of lessons and more personal support), one partner also indicated an interest in a book version of the intervention. In addition, three partners mentioned that they would like to see an additional lesson about bereavement, as illustrated by one of the partners: "From my personal experience, I would perhaps have liked an extra lesson that went more into detail about how things are once your partner has passed away. I mean, like an optional lesson."

We also asked partners to reflect on how we could improve the dissemination of such an intervention. Twelve partners said that they would have preferred an introduction of the intervention via a healthcare professional (such as an oncologist, nurse or social worker) in the hospital. There were different preferences regarding the optimal moment for introducing the intervention. Based on the answers provided by the partners, it appeared that every partner has his or her own moment in the cancer trajectory when support is needed, indicating that it might be important to offer the partners such an intervention at various times. This need is illustrated by the following testimony:

When somebody hears that [the cancer] has spread and there is nothing that can be done about it -I would not say something like, "Well, we offer a course you might like to attend." In any case, I would wait a little while and then, during the next stage lof the disease], offer the course a few times or at least point it out: "This is there for you, but if you don't want to make use of it, that's fine. But this is what we do offer." For indeed, there is so much attention on the patient and really no attention for those nearest [to him].

\section{Lessons learned from the intervention}

In response to the question regarding what the partners learned from the intervention, eleven partners answered in general terms such as: "I greatly profited from it. Not all parts were successful, not all lessons were effective, but still I greatly profited from it." Seven partners indicated that the intervention encouraged them to think about their situation. Four partners noted that the intervention was offered at a moment when they particularly needed help, and they liked the fact that they finally had received some attention, for instance: "I was so happy this came onto my path for, as a partner, I was so sad and worried. Of course, all the attention goes to the sick partner and only very few people really ask, 'And how are you doing?"'

Specific lessons learned could be divided into two categories: (1) lessons learned on the short-term that are 
processes that partners had experienced during or directly after the intervention and (2) lessons learned on the long-term or experiences regarding their well-being and relationship that partners were still experiencing at the time of the interview.

\section{Lessons learned on the short-term}

Lessons learned on the short-term could be divided into five categories: (1) insight and acknowledgement, (2) ACT- and self-compassion-related, (3) guidance and solutions, (4) positivity, and (5) attention as the caregiving partner (see Table 4).
Insight and acknowledgement Ten partners reported that the intervention helped them to better understand their situation and four of them found confirmation of their ability to cope with the difficult situation.

Eight partners indicated that it was pleasant to be acknowledged as a partner and to realize that their feelings and emotions are "normal" and not uncommon in their situation, for example:

The realization that one understands what is happening inside, by asking 'Why do I behave in this way now?' and 'Can I behave in a different way?'

Table 4 Lessons learned on the short-term

\begin{tabular}{|c|c|c|c|c|}
\hline Short-term effects & Total n & Subthemes & $\begin{array}{l}\text { Subtheme } \\
\text { Total } n\end{array}$ & Example quote \\
\hline \multirow[t]{3}{*}{$\begin{array}{l}\text { Insight and } \\
\text { acknowledgement }\end{array}$} & \multirow[t]{3}{*}{13} & $\begin{array}{l}\text { Better understanding of the } \\
\text { situation (psycho-education). }\end{array}$ & 10 & $\begin{array}{l}\text { "There were many emotions that I recognized, as you } \\
\text { know, but reading about them made me think, 'Yes, } \\
\text { that's how it is.' Like the expression 'emotional roller } \\
\text { coaster,' which suddenly appeared to be true also for } \\
\text { me. One is familiar with the phrase, but then suddenly } \\
\text { it becomes part of one's life." }\end{array}$ \\
\hline & & $\begin{array}{l}\text { Experiencing acknowledgement } \\
\text { and recognition. }\end{array}$ & 8 & $\begin{array}{l}\text { "I also felt confirmed in my feelings. So I am not crazy, } \\
\text { this is normal, this is a phase in my life and a process } \\
\text { to go through and that all people in my situation have } \\
\text { to face." }\end{array}$ \\
\hline & & $\begin{array}{l}\text { Confirmation of their ability } \\
\text { to cope with a difficult situation. }\end{array}$ & 4 & $\begin{array}{l}\text { "I felt like I had done really well. By following the course, } \\
\text { I discovered that this feeling of mine had been quite right, } \\
\text { for things did indeed go well." }\end{array}$ \\
\hline \multirow[t]{3}{*}{$\begin{array}{l}\text { ACT- and self- } \\
\text { compassion-related }\end{array}$} & \multirow[t]{3}{*}{11} & Be more (self-) compassionate. & 7 & $\begin{array}{l}\text { "So indeed, if I remember what was said, you know like } \\
\text { 'Do not demand too much from yourself,' 'Take time to } \\
\text { relax,' and the other sources of help, then I think: 'Yes, that } \\
\text { is right.' It really helped me a lot." }\end{array}$ \\
\hline & & Be more mindful. & 7 & $\begin{array}{l}\text { "It was really good to sometimes be really quiet, just to } \\
\text { listen for a moment and feel my feelings and be quietly } \\
\text { present to myself for some time." }\end{array}$ \\
\hline & & $\begin{array}{l}\text { Creating distance from your } \\
\text { own thoughts. }\end{array}$ & 5 & $\begin{array}{l}\text { "It was like letting your thought-factory go on a holiday, } \\
\text { so to say. I put [the mindfulness exercise] on my mp3 player } \\
\text { and sometimes took it with me to bed. So when I could } \\
\text { not sleep, I would play it." }\end{array}$ \\
\hline \multirow[t]{2}{*}{ Guidance and solutions } & \multirow[t]{2}{*}{9} & $\begin{array}{l}\text { Guidance to improve } \\
\text { communication. }\end{array}$ & 8 & $\begin{array}{l}\text { "They were very difficult subjects about which we first } \\
\text { explored independently from one another. We then talked } \\
\text { with each other about our answers." }\end{array}$ \\
\hline & & Helpful solutions. & 3 & $\begin{array}{l}\text { "Those exercises helped me to experience my meetings } \\
\text { with friends as relaxing. And indeed, why wouldn't you } \\
\text { share your worries?" }\end{array}$ \\
\hline Positivity & 6 & Positivity. & 6 & $\begin{array}{l}\text { "Well, we consciously looked at what we had done together, } \\
\text { also at the positive things, even though it was not all that } \\
\text { positive. Still, we said: 'We haven't done so badly, you know?' } \\
\text { Small things, they don't need to be so big." }\end{array}$ \\
\hline \multirow[t]{3}{*}{$\begin{array}{l}\text { Attention for me as } \\
\text { a partner }\end{array}$} & \multirow[t]{3}{*}{5} & Moments for myself. & 3 & $\begin{array}{l}\text { "Those are the moments you hold on to, you know? When } \\
\text { you think: 'Yes, how wonderful! I feel so relaxed now.' Those } \\
\text { are the moments, during the short time one has, that you try } \\
\text { to make your own." }\end{array}$ \\
\hline & & Telling my story. & 3 & $\begin{array}{l}\text { "The course really helped, because I was able to talk and write } \\
\text { about it and thus gain distance from it all. In daily life one } \\
\text { meets so very few people with whom you can share your } \\
\text { story. And in this case, I was able to share it." }\end{array}$ \\
\hline & & Structure. & 1 & $\begin{array}{l}\text { "It provides one with so many handles. And also with some } \\
\text { structure in all the chaos, so to say." }\end{array}$ \\
\hline
\end{tabular}


worked as a self-reflection. It was self-reflection, but also helped others [other people in this partner's life] to understand that it [this partner's behavior] is not unusual ...

ACT- and self-compassion-related Half of the partners reported having a positive experience with the mindfulness exercises. These exercises gave them rest, peace, time to reflect, and time to be fully aware of themselves and their surroundings, as illustrated in the following quote of one of the partners: "Indeed a short moment for oneself. Just for a moment, let me call it a conscious moment, or how shall I call it? A moment of recollection, one in which you really get quiet."

Seven partners indicated that they learned to be more (self-)compassionate. The intervention taught them to be more kind and caring towards themselves, to ask for help and to share their experiences with others. One partner said: "I told myself: 'That's not proper. You shouldn't enjoy yourself, because you've been through something very unpleasant.' And then I heard during the lesson: 'On the contrary, you really should enjoy yourself.' And that helped me a lot."

Five partners reported that the intervention helped them to create more distance from their own thoughts, as illustrated in the following quote:

Looking at oneself and, in some way, taking distance from oneself. If I may speak about Lesson 7, at a certain moment it says: If you were ten years older now, and you were still the same person with the same experiences, how would you look at yourself and which tips would you give yourself?' That was such a powerful way to take some distance from oneself: now I am ten years older and I am going to give myself some tips, which you can only formulate if you can take a distance. That is such a freeing experience, such a ... I can't explain it, but it's so incredibly good!

Guidance and solutions Most of the partners mentioned that the intervention provided guidance and useful solutions. In particular, the guidance to improve their communication with the patient was mentioned by eight partners. The texts and exercises stimulated conversations and provided an effective method to talk about sensitive topics like negative emotions and positive experiences, such as recollecting memories of special events like holidays or weddings. To illustrate this sub-category, one participant reported:

We talked about things we had not mentioned for a long time. It's like you protect each other. You don't tell each other certain things, because the situation is so difficult and you're just surviving. Things that are really important, things that were important before you don't think of them any longer. The lesson pointed this out to us, so we started talking about it all and that was so incredibly good.

Three partners mentioned that the intervention also provided helpful solutions for problems they had. Two indicated that the intervention provided useful tips on how to ask for help from the social network or how to decline it. Another partner indicated that the intervention provided some guidelines on how to become more self-reflective and that this self-reflection could help adjust one's behavior.

Positivity Six partners indicated that the intervention helped them to think and act more positively. One partner mentioned that it was fun to do the intervention because it brought new insights and was enjoyable. Another partner mentioned that the intervention brought positivity, but did not specify further. Three partners liked the fact that through the intervention they felt more connected with their partner. They were more aware of the positive aspects in their relationship and they valued these even more. Another partner reported having become more aware of the little things in life that can make a difference:

I followed that lesson during a particularly difficult time, and it greatly helped me to carefully think about the whole situation. Also about the rays of light, for it all seems so hard. And when I thought about those rays of light, I told myself: "Oh yes, remember? There still are so many nice things!

Attention for me as the caregiving partner Three partners reported that the intervention gave them the opportunity to have some time for themselves, and three partners valued the possibility to tell their story, as illustrated in the following quote: "There just happened to be elements in the course that simply were of great importance to me, especially the opportunity to tell my story." One partner felt that the intervention offered some structure during what felt like a chaotic and difficult time.

\section{Lessons learned on the long-term (experiences regarding well-being and relationship)}

Lessons learned on the long-term are experiences that the partners were still experiencing at the time of the interview. These can be divided into four categories (listed from the most to least mentioned): (1) ACT- and self- compassion-related skills, (2) positivity, (3) connectedness, and (4) personal growth. The categories and their subcategories are listed in Table 5. 
Table 5 Lessons learned on the long- term (experiences regarding well-being and relationship)

\begin{tabular}{|c|c|c|c|c|}
\hline Long-term effects & Total n & Subtheme & Subtheme Total $n$ & Example quote \\
\hline \multirow[t]{7}{*}{$\begin{array}{l}\text { ACT- and self- } \\
\text { compassion-related }\end{array}$} & \multirow[t]{7}{*}{14} & More (self-) compassionate. & 11 & $\begin{array}{l}\text { "What is it all about? At the side of a sick partner, } \\
\text { it is also about oneself. Yes, I see this also as a parent, } \\
\text { you know. It is a combination of things, also in your } \\
\text { role as an employee. As a partner too, but all of that } \\
\text { can only happen if you stay in it also for yourself." }\end{array}$ \\
\hline & & $\begin{array}{l}\text { More aware of the here and } \\
\text { now/more relaxed. }\end{array}$ & 8 & $\begin{array}{l}\text { "Just looking at things, not specifically, but with more } \\
\text { awareness, so to say." }\end{array}$ \\
\hline & & $\begin{array}{l}\text { Changing relationship with } \\
\text { thoughts (cognitive defusion). }\end{array}$ & 8 & $\begin{array}{l}\text { "Yes, some relaxation. At night you lie awake, and you } \\
\text { try to remember the course and then bring some quiet } \\
\text { to your thoughts and feelings." }\end{array}$ \\
\hline & & $\begin{array}{l}\text { Living in accordance with } \\
\text { personal values. }\end{array}$ & 7 & $\begin{array}{l}\text { "Yes, just say: 'I don't feel like it' or 'I don't have time for } \\
\text { that' or 'I won't make time for that.' " }\end{array}$ \\
\hline & & More acceptance of emotions. & 6 & $\begin{array}{l}\text { "Through the lessons I somewhat learned to think: Yes, } \\
\text { it is indeed very difficult and I is alright if I feel sad } \\
\text { sometimes." }\end{array}$ \\
\hline & & $\begin{array}{l}\text { Better communication about } \\
\text { what really matters. }\end{array}$ & 4 & $\begin{array}{l}\text { "It is also good to talk about it with my husband. He } \\
\text { doesn't talk very easily, but thanks to the topics that were } \\
\text { included, we also learned to really talk to each other." }\end{array}$ \\
\hline & & $\begin{array}{l}\text { Awareness of values in life } \\
\text { and relationship. }\end{array}$ & 4 & $\begin{array}{l}\text { "Especially 'what is really important.' One tends to easily } \\
\text { to just continue in the same old way." }\end{array}$ \\
\hline Positivity & 9 & Positivity (enjoy the little things). & & $\begin{array}{l}\text { "It is still a source of inspiration for me, just to think about } \\
\text { positive things and really dwell on them, like enjoying the } \\
\text { sunshine while taking a walk and those kinds of things. } \\
\text { Simply with real awareness." }\end{array}$ \\
\hline Connectedness & 6 & $\begin{array}{l}\text { Spouses got closer (more } \\
\text { connected). }\end{array}$ & & $\begin{array}{l}\text { "In any case it brought us together for a conversation. From } \\
\text { both sides, so to say, with the right instruments to better } \\
\text { understand each other and to help each other during the } \\
\text { whole process." }\end{array}$ \\
\hline Personal growth & 3 & Stronger and more resilient. & & $\begin{array}{l}\text { "Through the course, you move forward a bit and you grow } \\
\text { And the essence - you know it and you keep it alive." }\end{array}$ \\
\hline
\end{tabular}

ACT- and self-compassion-related skills Eleven partners felt more self-compassionate after the intervention. They realized that it is important to also focus on oneself, to be kind and caring not only towards the patient, but also towards oneself, as is illustrated by this quote:

I have also become a lot kinder to myself, also thanks to these lessons. Because I had to write down things and answer questions, I came to realize that I was also judging myself. And well, that is something I have done already for a long time. But now I naturally enter into a different phase of my life, and then it is so important to be very kind to myself, to allow myself some time to just do nothing for a little while. Or just to really take care of myself and pamper myself a little.

Eight partners reported being more aware of their surroundings, and they felt more calm and relaxed after the mindfulness exercises. For example, one of them said: "Also afterwards, the mindfulness exercise helped me to stay much calmer in everyday life... It helped me to be more conscious and calmer."

Eight partners reported that the intervention helped them to change their relationship with their thoughts, allowing them to see their thoughts just as thoughts and not the truth. One partner described this change:

One of the tips one receives is to think with every thought: 'That is a thought' or something like that, for instance 'I have thoughts that say...' That is really good because it shows that a thought is not the truth. You think it and it is just an image. And that gives one some kind of strength. I feel stronger by those thoughts, by formulating them in this way.

In addition, the intervention helped half of the partners to live in accordance with their personal values. Five partners indicated that they had learned to accept their needs, such as spending more time with their ill partner. Two partners indicated being stricter about protecting their personal boundaries. As one of them said:

I learned that it is always easy to drop everything and be there for everyone else while forgetting oneself. It is not right that everyone else runs your life. You should be able to say: "Wait there for a moment and don't come any further. 
Six partners reported feeling more acceptance towards their own emotions - like fear or worries, for example:

I learned something from the what-if questions. At the time, I was very busy with these kinds of questions. During that lesson, I came to understand that one has to learn how to deal with them. What if this, what if that - you have to learn to give such questions their place. That doesn't mean finding an answer to what-if, but rather that it is normal to have what-if questions and to know how to deal with them. That doesn't mean they direct your life, but that you give them their place, like: "This is the question to which I, for the moment, do not have an answer and that's that."

Four partners felt that they could better communicate about what really matters. The lessons stimulated conversations between partners and patients, and they felt that they remained more open towards each other, as is illustrated in the following quote:

Yes, afterwards we were more open towards each other about topics we would not have talked about so easily before. After the conversation, we carried on in a different way, so it absolutely brought us something.

Four partners reported that the intervention helped them to be more aware of their personal values in life and their relationship, For example:

I came to understand that the most important thing is my family. That is what it is all about. I realized my values ... I realized more clearly which are the most important values in my relationship and in my family situation.

Positivity Nine partners mentioned that they were more positive about their lives since they had completed the intervention. They were more aware of the small positive things in life that make life worth living. One partner said: "And now I do see [those rays of light], yes! Perhaps I did so before without realizing it, it happens so spontaneously. And now I think: ... Those rays of light make it all more pleasant."

Connectedness Six partners mentioned that they became closer and felt more connected to their partner. They reported that the intervention helped them to reflect on their relationship. For example, they indicated to be more aware of the importance of talking openly about feelings, needs and wishes and not just assuming what the other person might think. One partner also mentioned that she was more aware of the affection she felt for her partner. Kissing him was not just an automatic routine anymore, but she felt that this kiss actually meant something to her and to her partner. The following quote is an example of the connectedness the partners mentioned in our study: "It gave us a sense of belonging, like: Hey, we are actually quite happy together."

Personal growth Three partners reported that they became stronger and more resilient as a result of the intervention. They mentioned that the intervention itself was a source of energy or it provided them with information about where they can find helpful resources in order to improve their resilience and personal strength. One of the partners said: "Yes, during that time I really was ... sad. It was all so difficult, but thanks to the lessons, I came to see that I am much stronger than I thought I was."

\section{Discussion}

This study aimed to investigate the user-experiences with a Web-based self-help intervention based on ACT and self-compassion. We found that, in general, the intervention was positively appreciated and partners' learned lessons appeared to be helpful in supporting them to cope with the challenging situations they faced. Our findings can partly be explained by processes related to ACT- and self-compassion that were the basis of the intervention.

Most partners reported lessons learned on the shortand long-term related to these theories. Partners, for example, mentioned that the intervention made them aware of the importance of not only focusing on (the needs of) the patient and being kind and caring towards him or her, but to also treat themselves with the same amount of compassion. Some partners also mentioned that the intervention helped them to be more mindfully present and to accept their (negative) emotions instead of over-identifying or avoiding them, which refers to the A(cceptance) part of the ACT-model. The acceptance of negative emotions and sensations has often been found to be related to better mental health (e.g., [36]). In addition, the intervention helped partners to improve their ability to have more control over difficult thoughts, by creating a greater distance between their thoughts and themselves. This process, called cognitive defusion, is one of the core processes of the ACT model and it seems to be particularly important for partners of cancer patients because they often over-identify with unhelpful thoughts and feelings [1]. This result is in line with previous studies among other populations [37, 38]. Bacon et al. [37] examined the active processes of ACT in people experiencing psychotic disorders, and Mathias et al. [38] focused on the ACT processes in chronic pain patients. Both studies found that cognitive defusion is an ACT process that facilitated change in their participants. Partners also mentioned that our intervention helped them to become more aware of their personal 
values, more effective in communicating their values with the patient, and better able to commit to these values. These findings refer to the " $\mathrm{C}$ (hoose)" and "T(ake action)" of the ACT model and show that values and committed action may help partners of cancer patients. It seems that these processes can help them reorganize and rediscover their personal values and to live in accordance with them, despite the barriers caused by the cancer. Previous research has identified these ACT processes as contributing to positive change in other study populations, such as people with psychotic disorders [37] and patients with chronic pain [38].

Besides the processes related to ACT and self-compassion, our intervention seems to have also helped partners via a number of other processes such as insight and acknowledgement, positivity, possibility to tell their story, time for themselves, and feeling closer and more connected with the patient. Although these factors are not specifically related to $\mathrm{ACT}$ and self-compassion, they may be an important consequence of acceptance and self-compassion. In this respect, the impact of positivity is perhaps the most interesting. Nearly two-thirds of the partners reported that the intervention helped them to become more positive in life: allowing them to become aware of the little things in their lives and relationships that make life worth living (e.g., enjoying the weather; going for a walk; quality time with the family; a good conversation). Gaining acceptance towards one's emotions, becoming kinder towards oneself and acquiring awareness of one's values may result in an overall broader awareness, an improved experience of positive emotions, and an increase in enjoyment and appreciation of the positive things that remain in one's life. According to Fredrickson's broaden-and-build theory [39, 40], recurrent experiences of positive emotions (e.g., gratitude, love, feelings of joy) can increase a variety of personal resources such purpose in life, self-acceptance, mindfulness and positive relationships with others [41]. These resources can consequently lead to an increased life satisfaction and decreased levels of depressive symptoms. This aspect seems particularly crucial for partners of cancer patients because they are often confronted with many negative emotions, uncertain future perspectives and a high burden of responsibilities [1].

Another interesting factor that our findings revealed is the possibility of telling one's personal story. This factor seemed important for the partners because, by telling their story, they felt acknowledged. They also valued finally receiving some attention. During the patient's illness trajectory as well as within the social network of the partnership, the main focus often lies on the patient. As a consequence, the needs and concerns of the partners are often overlooked, and they have a minimal opportunity to tell their story. Web-based interventions aimed at this group can offer the attention and comfort they are vitally missing.
Besides offering clues about processes of (positive) change, our study also provided valuable information about the partners' appreciation of the intervention in general as well as specific elements. This information might be of interest for developers of future Webbased interventions for identical or similar groups. First, partners did not appreciate peer support as much as the other elements of the intervention. For example, they mentioned that they were not in need of peer contact or they were afraid of being confronted with negative stories. This result is in line with the outcomes of previous studies, which pointed out that people often fear peer support because they are afraid of hearing negative stories [32, 33]. While we tried to minimize this risk by offering different options of peer support, according to the users' experience, it seems that this approach was not sufficient to reassure the partners. Second, whereas previous research showed that personal feedback about a participant's progress is a valuable addition to an intervention $[9,42]$, the partners in our study mentioned that they would have liked the feedback to be more personal and to discuss some matters more deeply. For this specific group, more personal feedback could be important because, within the patient's care environment, often little or no room exists for the partners to tell their story or to express their concerns and questions. A more blended approach of the intervention (a combination of Webbased and face-to-face components) could be a possible solution to this problem [43]. Third, whereas some partners particularly appreciated the 'tunneled' structure of the current intervention, others preferred a less strict structure. As described earlier, we chose to deliver the content in a step-by-step format with a predefined order because we thought that this particular sequence of modules would be most beneficial for the partners, as it would give the partners sufficient time to process all the information.

Finally, regarding the dissemination of this intervention, partners suggested that healthcare professionals in hospitals (e.g., oncologists, nurses or social workers) should introduce the intervention not just once, but several times during the patient's cancer trajectory. Partners seem to have different needs regarding when they might want to obtain support. Some partners would like to receive a psychological intervention immediately after the diagnosis, whereas others want to participate when they think it is necessary. We have to consider that partners often do not ask for help. Often they are not aware of their own health problems or they even neglect them because the patient's wellbeing is their utmost priority (e.g., [44-46]). We expect that by offering an intervention (at various stages) to the partners, they may be more aware of the fact that 
they are at risk of developing physical or psychological health problems and that receiving help is not unusual. This multiple introduction of the intervention may help to lower partners' threshold of asking for help for themselves.

The results from our qualitative study suggest that the training of ACT-related processes and self-compassion can indeed help partners of cancer patients to cope with the challenging situation they are facing. The outcomes of this study need to be interpreted with caution. First, it could be possible that the partners who were willing to participate in this study were initially more positive or negative about the intervention than partners who did not want to participate. This might indicate that our results may not be generalizable. Second, results may not be representative for all participants of the intervention because of the rather small study sample. However, the personal- and cancer-related characteristics of this sample are comparable to the characteristics of all participating partners and we reached data saturation which may suggest that the results are reliable. Third, this study was retrospective, indicating that the results relied on participants' memories of the intervention. As aforementioned, the time since participation varied among participants (mean time since intervention was about eight months). In anticipation of this possible limitation, before interviewing the participants, we provided all of them with a short summary of every lesson of the intervention. Yet, half of the partners still had difficulties remembering specific elements of the intervention, for example a specific lesson or exercise. However, all of the partners were able to describe general experiences with the intervention. A fourth limitation is related to the positioning and reflexivity of the researchers, since five of the researchers had worked with the randomized controlled trial. To minimize this bias, we included a sixth co-author (JJ) who was not part of the regular research team. JJ conducted and transcribed the interviews and was also involved in the data-analysis. Furthermore, we constantly reflected on our process when we coded and interpreted our data. We were cautious to not only present opinions of participants who were positive about the intervention, but to also display critical sounds regarding the intervention. Quantitative effect studies are, of course, necessary to evaluate the effects of the intervention on psychological distress, caregiver burden, mental well-being and other outcome measures. Therefore, we are currently conducting a randomized controlled trial.

\section{Conclusions}

The Web-based self-help intervention, based on ACT and self-compassion, was appreciated by partners of cancer patients and helped them to cope with negative emotions, thoughts, and their own suffering; to practice self-kindness; and to clarify values based on their difficult recent experiences. In addition, the intervention supported them to obtain insight and acknowledgement, positivity, to tell their story, make time for themselves, and feel closer and more connected with the patient.

\section{Acknowledgements \\ The authors would kindly like to thank the participants for their time, effort, and willingness to share their experiences. \\ Funding \\ Parts of this study were supported by a grant from the Dutch Cancer Society (KWF)/Alpe d'HuZes; Contract grant number: 5248.}

\section{Availability of data and materials}

The datasets generated during and/or analyzed during the current study are not publicly available due to the qualitative character of the data and in order to protect the anonymity of the participants. Datasets are available from the corresponding author on reasonable request.

\section{Authors' contributions}

All authors made substantial contributions to conception and design of this study. NK, CHCD and JJ contributed to the acquisition of the data. The gathered data was analyzed and interpreted by NK, CHCD and JJ and these three authors also drafted the manuscript. The other authors participated in revising the manuscript critically for important intellectual content. All authors gave their final approval of the version to be submitted and any revised version.

\section{Competing interests}

The authors declare that they have no competing interests.

\section{Consent for publication}

Not applicable.

\section{Ethics approval and consent to participate}

The Twente Medical Ethical Committee (Enschede, The Netherlands) approved this study in the context of a larger RCT (file number P13-17; Dutch trial register: NTR4035). All procedures performed in studies involving human participants were in accordance with the ethical standards of the institutional and/or national research committee and with the 1964 Helsinki declaration and its later amendments or comparable ethical standards. Participants had given their oral informed consent before the interview took place. Written informed consent had already been given in the context of the RCT.

\section{Author details}

'Department of Psychology, Health \& Technology, University of Twente, P.O. Box 217, 7500 AE Enschede, The Netherlands. ${ }^{2}$ Roessingh Research \& Development, P.O. Box 310, 7500 AH Enschede, The Netherlands.

${ }^{3}$ Department of Clinical, Neuro-\& Developmental Psychology, Section Clinical Psychology, VU University, van der Boechorststraat 1, 1082 BT Amsterdam, The Netherlands. ${ }^{4}$ Department of Otolaryngology/Head and Neck Surgery, VU University Medical Center, P.O Box 7057, 1007 MB Amsterdam, The Netherlands.

Received: 13 August 2016 Accepted: 8 February 2017

Published online: 28 February 2017

\section{References}

1. Stenberg U, Ruland C, Miaskowski C. Review of the literature on the effects of caring for a patient with cancer. Psycho Oncol. 2010;19(10):1013-25.

2. Sklenarova H, Krümpelmann A, Haun MW, Friederich H-C, Huber J, Thomas M, et al. When do we need to care about the caregiver? Supportive care needs, anxiety, and depression among informal caregivers of patients with cancer and cancer survivors. Cancer. 2015;121(9):1513-9. doi:10.1002/cncr.29223.

3. Braun M, Mikulincer M, Rydall A, Walsh A, Rodin G. Hidden morbidity in cancer: spouse caregivers. J Clin Oncol. 2007;25(30):4829-34. 
4. Eysenbach G. What is e-health? J Med Internet Res. 2001; 3(2). doi:10.2196/ jmir.3.2.e20.

5. Hayes SC, Strosahl KD, Wilson KG. Acceptance and commitment therapy. New York: Guilford Press; 1999.

6. Harris R. ACT made simple: An easy-to-read primer on acceptance and commitment therapy. Oakland: New Harbinger Publications; 2009.

7. Hayes S, Luoma J, Bond F, Masuda A, Lillis J. Acceptance and commitment therapy: model, processes and outcomes. Behav Res Ther. 2006:44(1):1-25.

8. Trompetter HR. ACT with pain: measurement, efficacy and mechanisms of acceptance \& commitment therapy. Enschede: Universiteit Twente; 2014.

9. Fledderus M, Bohlmeijer E, Pieterse M, Schreurs K. Acceptance and commitment therapy as guided self-help for psychological distress and positive mental health: a randomized controlled trial. Psychol Med. 2012 42(03):485-95

10. Fledderus M, Bohlmeijer E, Smit F, Westerhof G. Mental health promotion as a new goal in public mental health care: a randomized controlled trial of an intervention enhancing psychological flexibility. Am J Public Health. 2010; 100(12):2372-8.

11. Pots WT, Fledderus M, Meulenbeek PA, Peter M, Schreurs KM, Bohlmeijer ET: Acceptance and commitment therapy as a web-based intervention for depressive symptoms: randomised controlled trial. The British Journal of Psychiatry. 2016;208(1):69-77.

12. Neff KD. The development and validation of a scale to measure selfcompassion. Self and identity. 2003;2(3):223-50. doi:10.1080/ 15298860390209035

13. Neff K. Self-compassion: An alternative conceptualization of a healthy attitude toward oneself. Self Identity. 2003;2(2):85-101. doi:10.1080/ 15298860390129863.

14. MacBeth A, Gumley A. Exploring compassion: A meta-analysis of the association between self-compassion and psychopathology. Clin Psychol Rev. 2012;32(6):545-52.

15. Hollis-Walker L, Colosimo K. Mindfulness, self-compassion, and happiness in non-meditators: A theoretical and empirical examination. Pers Individ Dif. 2011;50(2):222-7.

16. Neff KD, Pisitsungkagarn K, Hsieh Y-P. Self-compassion and self-construal in the United States, Thailand, and Taiwan. J Cross-Cult Psychol. 2008;39(3):267-85.

17. Neff KD, Beretvas SN. The role of self-compassion in romantic relationships. Self Identity. 2013:12(1):78-98. doi:10.1080/15298868.2011.639548.

18. Sbarra DA, Smith HL, Mehl MR. When leaving your ex, love yourself observational ratings of self-compassion predict the course of emotional recovery following marital separation. Psychol Sci. 2012;23(3):261-9.

19. Stenberg U, Ekstedt M, Olsson M, Ruland CM. Living close to a person with cancer: a review of the international literature and implications for social work practice. J Gerontol Soc Work. 2014;57(6-7):531-55. doi:10.1080/ 01634372.2014 .881450

20. Köhle N, Drossaert CHC, Oosterik S, Schreurs KM, Hagedoorn M, van UdenKraan CF, et al. Needs and preferences of partners of cancer patients regarding a web-based psychological intervention: a qualitative study. JMIR cancer. 2015;1(2), e13.

21. Shannon CS. 'I was trapped at home': Men's experiences with leisure while giving care to partners during a breast cancer experience. Leis Sci. 2015; 37(2):125-41. doi:10.1080/01490400.2014.973128.

22. Neff KD, Faso DJ. Self-compassion and well-being in parents of children with autism. Mindfulness. 2015;6(4):938-47.

23. Tirch D, Schoendorff B, Silberstein LR. The ACT practitioner's guide to the science of compassion: Tools for fostering psychological flexibility. Oakland: New Harbinger Publications; 2014.

24. Spillers RL, Wellisch DK, Kim Y, Matthews A, Baker F. Family caregivers and guilt in the context of cancer care. Psychosomatics. 2008;49(6):511-9.

25. Neff KD, Germer CK. A pilot study and randomized controlled trial of the mindful self-compassion program. J Clin Psychol. 2013;69(1):28-44.

26. Lewin S, Glenton C, Oxman AD. Use of qualitative methods alongside randomised controlled trials of complex healthcare interventions: Methodological study. BMJ (Online). 2009:339(7723):732-4. doi:10.1136/bmj.b3496.

27. Campbell M, Fitzpatrick R, Haines A, Kinmonth AL. Framework for design and evaluation of complex interventions to improve health. Br Med J. 2000; 321(7262):694

28. Köhle N, Drossaert CHC, Schreurs KMG, Hagedoorn M, Verdonck-de Leeuw IM, Bohlmeijer ET. A web-based self-help intervention for partners of cancer patients based on Acceptance and Commitment Therapy: a protocol of a randomized controlled trial. BMC Public Health. 2015;15(1):303.
29. Guest G, Bunce A, Johnson L. How many interviews are enough? An experiment with data saturation and variability. Field methods. 2006;18(1):59-82

30. Oinas-Kukkonen H, Harjumaa M. Persuasive systems design: Key issues, process model, and system features. Commun Assoc Inf Syst. 2009;24(1):485-500.

31. Lehto T, Oinas-Kukkonen H. Persuasive Features in Web-Based Alcohol and Smoking Interventions: A Systematic Review of the Literature. J Med Internet Res. 2011;13(3), e46. doi:10.2196/jmir.1559.

32. van Uden-Kraan CF, Drossaert CHC, Taal E, Shaw BR, Seydel ER, van de Laar MAFJ. Empowering processes and outcomes of participation in online support groups for patients with breast cancer, arthritis, or fibromyalgia. Qual Health Res. 2008:18(3):405-17.

33. Van der Vaart R, Drossaert CHC, Taal E, van de Laar MAFJ. Experiences and preferences of patients with rheumatic diseases regarding an interactive health communication application. Int J Adv Life Sci. 2010;3(3\&4):143-53.

34. Brod M, Tesler LE, Christensen TL. Qualitative research and content validity: developing best practices based on science and experience. Qual Life Res. 2009;18(9):1263.

35. Corbin JM, Strauss A. Grounded theory research: Procedures, canons, and evaluative criteria. Qual Sociol. 1990;13(1):3-21.

36. Levitt JT, Brown TA, Orsillo SM, Barlow DH. The effects of acceptance versus suppression of emotion on subjective and psychophysiological response to carbon dioxide challenge in patients with panic disorder. Behav Ther. 2004; 35(4):747-66. doi:10.1016/S0005-7894(04)80018-2.

37. Bacon T, Farhall J, Fossey E. The active therapeutic processes of acceptance and commitment therapy for persistent symptoms of psychosis: Clients' perspectives. Behav Cogn Psychother. 2014:42(4):402-20.

38. Mathias B, Parry-Jones B, Huws JC. Individual experiences of an acceptancebased pain management programme: an interpretative phenomenological analysis. Psychol Health. 2014;29(3):279-96.

39. Fredrickson BL. What good are positive emotions? Rev Gen Psychol. 1998. 2(3):300.

40. Fredrickson BL. The role of positive emotions in positive psychology: The broaden-and-build theory of positive emotions. Am Psychol. 2001;56(3):218.

41. Fredrickson BL, Cohn MA, Coffey KA, Pek J, Finkel SM. Open hearts build lives: positive emotions, induced through loving-kindness meditation, build consequential personal resources. J Pers Soc Psychol. 2008:95(5):1045.

42. Kelders DSM. Understanding adherence to web-based interventions. Enschede: Universiteit Twente; 2012

43. Wentzel J, van der Vaart R, Bohlmeijer ET, van Gemert-Pijnen JE. Mixing online and face-to-face therapy: how to benefit from blended care in mental health care. JMIR mental health. 2016;3(1), e9.

44. Ussher J, Perz J, Hawkins Y, Brack M. Evaluating the efficacy of psycho-socia interventions for informal carers of cancer patients: a systematic review of the research literature. Health Psychol Rev. 2009;3(1):85-107.

45. Northouse L, Katapodi M, Song L, Zhang L, Mood D. Interventions with family caregivers of cancer patients, meta-analysis of randomized trials. CA Cancer J Clin. 2010;60(5):317-39.

46. Harding R, Higginson IJ. What is the best way to help caregivers in cancer and palliative care? A systematic literature review of interventions and their effectiveness. Palliat Med. 2003;17(1):63-74. doi:10.1191/0269216303pm667oa.

\section{Submit your next manuscript to BioMed Central and we will help you at every step:}

- We accept pre-submission inquiries

- Our selector tool helps you to find the most relevant journal

- We provide round the clock customer support

- Convenient online submission

- Thorough peer review

- Inclusion in PubMed and all major indexing services

- Maximum visibility for your research

Submit your manuscript at www.biomedcentral.com/submit 